their Service experience, and each has been teaching and practising orthoptics for a number of years. Therefore Mr. Lyle is to be congratulated on having chosen worthy successors of Miss Jackson, the latter having now retired.

The format of this new edition, with its increased width of page, allows more scope for the larger illustrations, especially the Hess charts, and much important new material has been added. We predict a warm welcome for this amply-illustrated volume, which has been well printed on high-quality paper, and enclosed within dignified covers. A new edition of Practical Orthoptics was badly needed, not only because of the fresh methods of binocular stimulation devised since 1940, but also for the sake of stressing differential prognosis. Thus we read' on pp. 34-35: "On no account should treatment be continued unless progress is being made . . . time should not be wasted giving orthoptic treatment to patients whose binocular anomalies are unlikely to benefit from such treatment. Every orthoptist should clearly understand the limitations of orthoptic treatment as well as its advantages."

Realism is the keynote of the work under review. The importance of preliminary investigation and accuracy of diagnosis are dúly emphasised. The serious reader will soon notice that $\mathrm{Mr}$. Lyle avoids facile generalisations, and is careful to illustrate his principles by actual case-records. Torticollis-a subject which has often been clouded by obscure descriptions in the past-is lucidly expounded, and the account of cases exhibiting abnormal head posture will repay detailed study. Mr. Lyle's wide experience in the refractive, orthoptic and operative treatment of squint and other anomalies of ocular muscle balance is backed by his constant awareness of the human problem. That is why he insists upon the need for encouragement and cheerfulness on the part of the orthoptist, with the object of strengthening the patient's will to be cured. Another great asset is Mr. Lyle's special knowledge of neuroophthalmology, which is evident on nearly every page. Practical Orthoptics is a distinguished piece of work, the influence of which will be enormous throughout and beyond the English-speaking world.

\title{
CORRESPONDENCE
}

\section{GLIOMA OF THE RETINA}

To the Editorial Committee of

The British Journal of Ophthalmology

DEAR SIRS,-I should be glad of the help that some of your readers may be able to give on this issue: To what extent is an 
individual successfully treated for glioma of the retina liable to pass the affection on to his children?

That there is a hereditary factor in glioma of the retina is fully established. What is not known is whetherall gliomata are hereditary. This could only be established if adequate information were available on the progeny of individuals successfully treated. There must be by now many patients who have reached adult life having lost one or both eyes in infancy (or retained an eye after successful radiotherapy). Some of these adults may have families, and it would be a great help to know whether any of their children have developed glioma.' For a clear answer it is, of course, necessary to have information on children who are not affected as well as on children who are affected. If, as is assumed, glioma of the retina is dominant, 50 per cent. of the children of surviving patients should be affected unless modifying factors disturb the ratio.

In most dominant conditions tracing the family backward gives enough information. In the case of a highly lethal affection like glioma of the retina this procedure is not available. Moreover, there is good reason for believing that most cases of glioma represent new mutations rather than the continuance of a line of affected. individuals.

I should be grateful if such of your readers who have the relevant information could let me have the following particulars:

(a) Name and a short personal history of the individual affected with glioma, and an indication, if available, as to the occurrence of glioma in relatives.

(b) The number (and, if possible, the sequence) of children in the second generation.

(c) Indication as to which, if any, of these children show glioma.

(d) In any glioma patients information as to whether the glioma was unilateral or bilateral would be appreciated.

Yours faithfully, ARNOLD SORSBY.

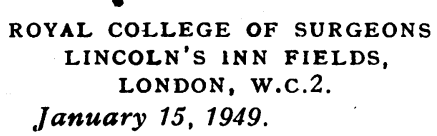

To the Editorial Committee of

The BRitish Journal of Ophthalmology

DEAR SIRS, - The infection of the conjunctival sac by larvae of flies (maggots) is relatively rare in Western Europe (Duke-Elder, Vol. II), and most of the cases recorded have been infections by the hypoderma bovis.

Whilst in Malta I obtained larvae specimens of oestrus ovis and submit the following case history:- 
During July a Naval officer attended the Ophthalmic Department of the Royal Naval Hospital, Malta, complaining that following a swim in the sea the previous day something had entered his right eye, producing redness and irritation. Examination revealed three small worms crawling on the conjunctiva, each approximately $1.5 \mathrm{~mm}$. long.

These were removed with forceps and the eye irrigated. In 48 hours the patient had recovered from the traumatic conjunctivitis.

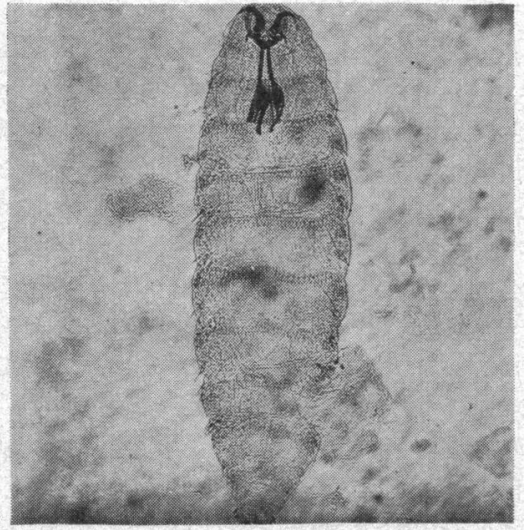

FIG. 1.

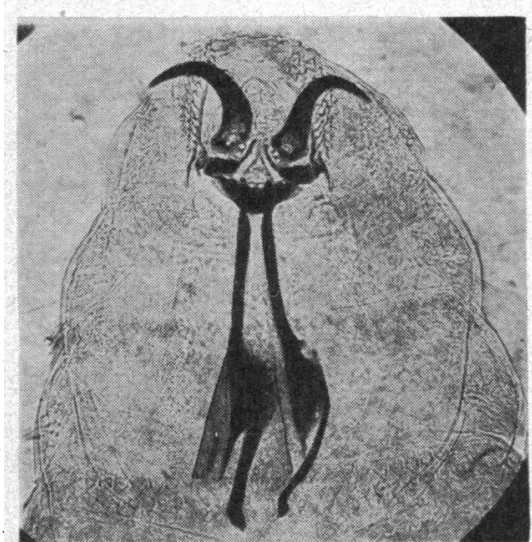

FIG. 2.

(During that period he used protargol drops 3 per cent.). No further attendances were necessary.

The specimens of the "worms" were mounted and have now been identified as larvae of oestrus ovis.

I am submitting two photographs of the larvae in case they should be of interest.

ROYAL INFIRMARY,

Yours faithfully, •

GEORge E. RoBINSON.

Surg. Lt.-Cdr. R.N.V.R. Late Ophthalmic Specialist,
Royal Naval Hospital, Malta.

SHEFFIELD, 6 .

December 2, 1948.

The ROYAL INSTITUTE of PUBLIC HEALTH \& HYGIENE

Spring Session, 1949-Lectures to be delivered in

The Lecture Hall, 28, Portland Place, W.1.

April $20 \quad \ldots \quad$ (1) "Occupational Eye Diseases and Injuries" (Illustrated)

April $27 \quad$... (2) "Occupational Eye Diseases and Injuries" (Illustrated) At 3.30 p.m. on each day.

Lecturer: Joseph Minton, F.R.C.S.

Chairman: Charles B. Goulden, O.B.E., M.A., M.C., M.D.; F.R.C.S.

The next meeting of the Oxford Ophthalmological Congress will be held on July 7,8 and 9,1949 , at Oxford. 